\title{
Pterocarpus Marsupium and Gymnema Sylvestre Powder in Alleviation of Biochemical Abnormalities Associated with Human Type 2 Diabetes Mellitus
}

\author{
Sunil Mahajan ${ }^{1}$, Pratibha Chauhan ${ }^{1}$, Meerambika Mishra ${ }^{2}$, Dhananjay Yadav ${ }^{3}$, Urmila Jarouliya ${ }^{1}$ and GBKS \\ Prasad ${ }^{1 *}$ \\ ${ }^{1}$ Centre for Translational Research, Jiwaji University, India \\ ${ }^{2}$ School of Life Sciences, Sambalpur University, India
}

${ }^{3}$ Department of Medical Biotechnology, Yeungnam University, South Korea

Submission: September 26, 2017; Published: August 28, 2018

*Corresponding author: GBKS Prasad, Centre for Translational Research, School of Studies in Biochemistry, Jiwaji University, Gwalior, India, Tel: +91-9229197619; Fax: +91 -751-2341768; Email: gbksprasad@gmail.com

Abstract

Objectives: This observational study investigated the antihyperglycemic, antihyperlipidemic and antioxidant potential of Pterocarpus marsupium (Vijaysaar) and Gymnema sylvestre (Gudmar) ("VG") Therapy in patients with type 2 diabetes mellitus.

Methods: Subjects with type 2 diabetes mellitus were administered a phytochemical formulation consisting $50 \mathrm{ml}$ of aqueous extract derived from $3 \mathrm{gm}$ "VG" powder was administered twice a day for six months. The blood glucose levels were monitored at monthly intervals; glycosylated hemoglobin, lipid profile and biomarkers of oxidative stress, liver and kidney functions were monitored at three monthly intervals.

Results: Daily administration of the "VG" Therapy regularly for 6 months resulted in significant reduction of blood glucose and glycosylated hemoglobin levels. There was also a significant increase in high-density lipoprotein cholesterol levels with concomitant decrease in total cholesterol, triglyceride, low-density lipoprotein cholesterol, and very-low-density lipoprotein levels. Significant improvement in the biochemical markers of oxidative stress was recorded.

Conclusion: The results suggest that herbal formulation "VG" is beneficial in improving glucose and lipid homeostasis in type 2 diabetics and may serve as an adjunct therapy.

Keywords: Hyperglycemia; Dyslipidemia; Oxidative stress; Type 2 diabetes mellitus; Pterocarpus marsupiu; Gymnema sylvestre

Abbreviations: BMI: Body Mass Index; DBP: Diastolic Blood Pressure; FPG: Fasting Plasma Glucose; GSH: Reduced Glutathione; HbA1c: Glycosylated Haemoglobin; HDL: High-Density Lipoprotein Cholesterol; LDL: Low-Density Lipoprotein Cholesterol; PPG: Postprandial Glucose; SBP: Systolic Blood Pressure; SOD: Superoxide Dismutase; SGOT: Serum Glutamate Oxaloacetate Transaminase; SGPT: Serum Glutamate Pyruvate Transaminase; TBARS: Thiobarbituric Acid Reacting Substances; VLDL: Very low-density lipoprotein cholesterol; VG: Vijaysaar and Gurmar

\section{Introduction}

Type 2 diabetes mellitus is reaching epidemic proportions worldwide and is a complex metabolic disorder characterized by hyperglycemia and dysregulated lipid metabolism [1,2]. Abdominal obesity and dyslipidemia (increased triglycerides, high LDL-cholesterol and low HDL-cholesterol), and hypertension, as well as altered platelet function [3] are the major risk factors contributing to type 2 diabetes. The metabolic defects that underlie the development of type 2 diabetes may include islet $\beta$-cells dysfunction, hyperglucagonemia, elevated endogenous glucose production, development of peripheral insulin resistance, inflammation of adipose tissue, and dysregulation of adipokines production [4]. Chronic elevation of blood glucose which is a central factor in the production of reactive oxygen species (ROS) [5] which in turn promote cellular damage and contribute to the development and progression of diabetic complications, such as cardiovascular disease, nephropathy, retinal blindness, neuropathy, and peripheral gangrene [6]. The conventional allopathic drugs, sulfonylureas, meglitinides, biguanides, metformin, thiazolidinediones, miglitol, acarbose, etc. although effective [7], are associated with minor or major side effects on long term use [8]. Statins used in the treatment of dyslipidemia have their own limitations [9].

Plant based Indian traditional medicines such as Ayurveda have been used since ancient times in the treatment of diabetes [10]. Ethnobotanical studies of traditional herbal medicine used for diabetes have identified more than 1,200 species of plants 
with hypoglycemic activity [10]. Medicinal plants are frequently considered to be less toxic and free from side effects than synthetic ones. The antidiabetic effects of several plant extracts and herbal formulations and their bioactive compounds have been identified and characterized for the treatment of diabetes mellitus [11,12].

Polyherbal formulations [13], have been shown to exhibit antidiabetic, antihyperlipidemic and antioxidant potential in animal models as well as in diabetic patients [14]. The phytochemical based formulations consisting of multiple herbs are liable to produce a large number of metabolites that may act on multiple targets in the body and hence, polyherbal formulations (Which are used in traditional practice) are preferred over mono therapeutic ones. Although, phytochemical based formulations have extensively been used, studies on their proof of efficacy are limited [15].

Gymnema sylvestre (Gudmar) is a climber grown in tropical forests of South-East and belongs to the family Asclepiadaceae G. sylvestre is considered to have a great anti-diabetic potential and used in several anti-diabetic formulations. There are several reports in animal models as well as in diabetic patients which shows that extract of $G$. Sylvestre leaves have anti-diabetic potential $[16,17]$, and these effects are attributes due to increase in insulin secretion [18]. Pterocarpus marsupium (Vijaysaar) is the most versatile plant with a wide spectrum of biological activities and belongs to the family Fabaceae. The P. marsupium is reported to be anti-diabetic and associated with anti-obesity, anti-hyperlipidemic, antiinflammatory, anti-oxidative, antitumorigenic functions [19-21]. The aim of this study is to explore the therapeutic potential of combined effects of the regular consumption of Pterocarpus marsupium and Gymnema sylvestre in human subjects with type 2 diabetes mellitus.

\section{Materials and Methods}

\section{Study sample}

A total of 45 type 2 diabetic patients attending the weekend diabetes clinic run by the Centre for Translational Research, School of Studies in Biochemistry, Jiwaji University, India expressed their willingness to participate in the study. Of these, 35 subjects met the inclusion criteria who were then explained the necessity of maintaining defined lifestyle pattern during the course of the study. Out of 35 subjects, 8 subjects were eliminated during the course of the study due to non-compliance. The remaining 27 subjects took the drug regimen regularly as per the experimental design. Figure 1 shows the number of subjects enrolled and drop outs during the course of study. The patients' baseline characteristics are summarized in (Table 1).

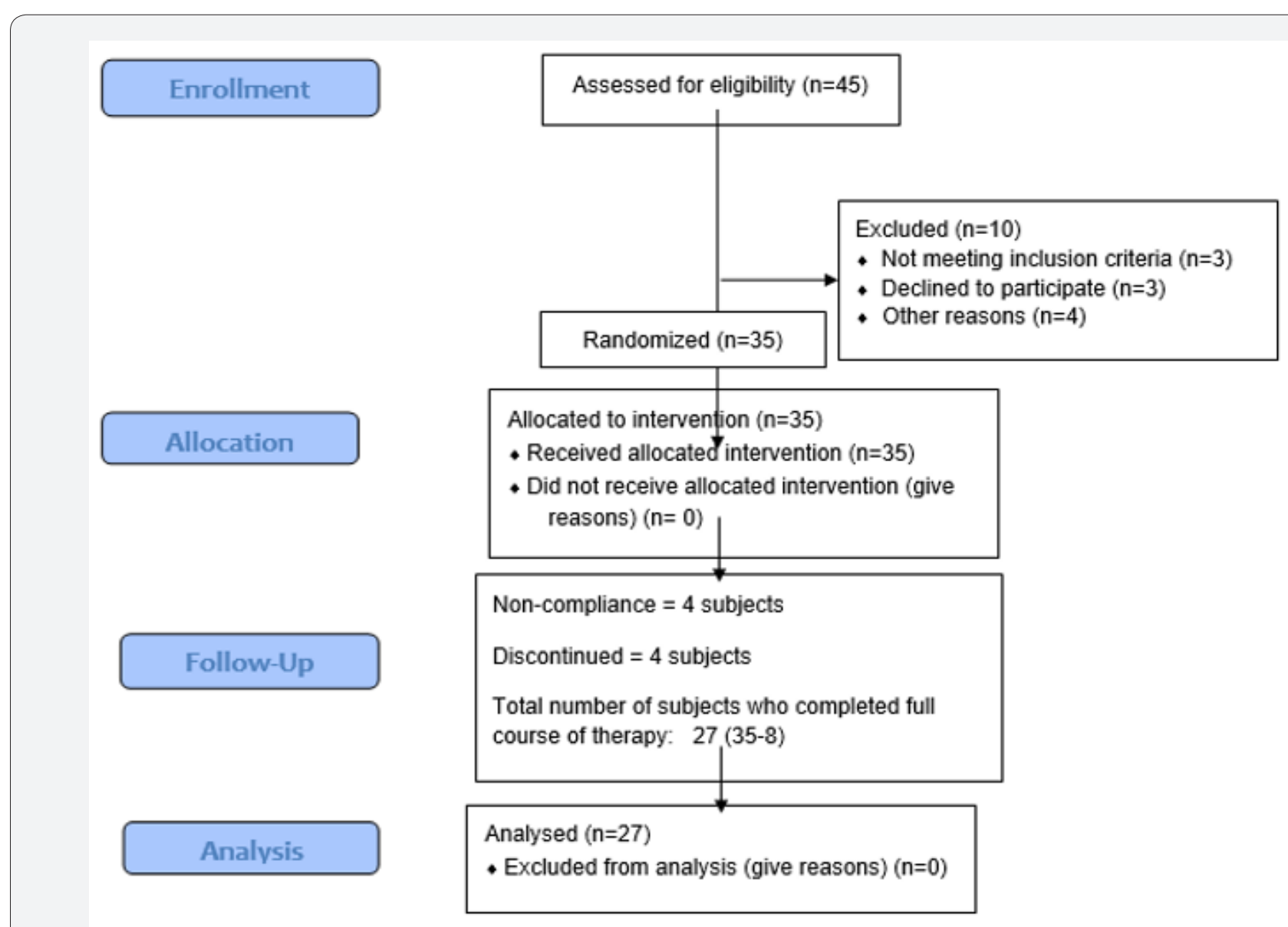

Figure 1: Flow diagram indicating the number of subjects enrolled and drop outs during the course of study. 
Table 1: Baseline characteristics of study population.

\begin{tabular}{|c|c|}
\hline Measure & $\mathbf{n = 2 7}$ \\
\hline Sex (n), (Male/Female) & $22 / 5$ \\
\hline Age (years) & $53.11 \pm 1.56$ \\
\hline Duration of disease (years) & $5.42 \pm 1.16$ \\
\hline Weight $(\mathrm{kg})$ & $69.98 \pm 1.95$ \\
\hline Height $(\mathrm{cm})$ & $166.67 \pm 1.52$ \\
\hline BMI $(\mathrm{kg} / \mathrm{m} 2)$ & $25.21 \pm 0.64$ \\
\hline SBP $(\mathrm{mm} \mathrm{Hg})$ & $133.70 \pm 2.59$ \\
\hline DBP $(\mathrm{mm} \mathrm{Hg})$ & $81.70 \pm 0.97$ \\
\hline FBG $(\mathrm{mg} / \mathrm{dl})$ & $168.75 \pm 8.44$ \\
\hline PPBG $(\mathrm{mg} / \mathrm{dl})$ & $256.03 \pm 10.22$ \\
\hline HbA1c $(\%)(\mathrm{mmol} / \mathrm{mol})$ & $7.68 \pm 0.21(60.4)$ \\
\hline
\end{tabular}

Data are expressed as Mean \pm SEM;

BMI-Body mass index; SBP-Systolic blood pressure; DBP- Diastolic blood pressure; FBG-Fasting blood glucose; PPBG-Post prandial blood glucose; HbA1c: Glycosylated Haemoglobin.

\section{Study design}

The study design included following steps:

a) Selection of patients meeting inclusion criteria and those consented to participate in the study.

b) Measurement of anthropometric and biochemical parameters once before and at selected intervals during the course of the study.

c) Administration of "VG" Therapy in defined dose daily for a period of 6 months.

d) Measurement of parameters at the end of the study.

e) Analysis of the data.

\section{Inclusion criteria}

a) Non-insulin dependent diabetes diagnosed, as per the criteria of the World Health Organization;

b) Both genders between the ages of 30-65 years;

c) Body Mass Index in the range of 18.5 to 40;

d) Participants who understood the benefits of the study and signed a written informed consent;

\section{Exclusion criteria}

a) Presently using other blood glucose regulating agents;

b) Daily intake of alcoholic beverages;

c) Smokers consuming more than 1 pack/day;

d) Patients diagnosed as type I and insulin dependent type II diabetics;

e) Patients with hepatic or renal disease, pancreatitis, cardiac problems, uncontrolled hypertension, malnutrition and severe immune deficiency.

f) Non-compliance during the course of study.
Before starting the study all participating subjects were given a verbal explanation about the objectives of the study, nature of drug formulation (Kwath) to be consumed daily, ("VG" Therapy) rationale and duration of therapy in local language. They were asked to avoid a carbohydrate rich diet and advised regular walking for about 4-5 km during the course of study. The patients who consented to participate in the study were registered, anthropometric measurements; weight, height and waist were recorded at the beginning and at selected intervals during the study period. The patients were kept exclusively on "VG" therapy.

\section{Composition of drug (VG) formulation}

The "VG" formulation consisted of a mixture of Pterocarpus marsupium (Vijaysaar), and Gymnema sylvestre (Gurmar) (Table 2) and was provided by the M/S Dindayal Industries Ltd. India. The individual plants were identified by Prof. A.K. Jain, School of Studies Botany, Institute of Ethnobiology Jiwaji University Gwalior. Voucher specimens were prepared and deposited at the Centre (IOE-501 and IOE-505).

Table 2: Details of herbs used in "VG" herbal formulation.

\begin{tabular}{|c|c|c|c|c|}
\hline $\begin{array}{c}\text { Botanical } \\
\text { name }\end{array}$ & $\begin{array}{c}\text { General } \\
\text { Indian } \\
\text { name }\end{array}$ & Family & Part used & Harberium \\
\hline & & Asclepiadaceae & Leaves & IOE-501 \\
\hline $\begin{array}{c}\text { Gymnema } \\
\text { sylvestre } \\
\text { (Retz.) R.Br. }\end{array}$ & Gurmar & No. & \\
\hline $\begin{array}{c}\text { Pterocarpus } \\
\text { marsupium } \\
\text { Roxb. }\end{array}$ & Vijaysaar & Fabaceae & $\begin{array}{c}\text { Heart } \\
\text { wood }\end{array}$ & IOE-505 \\
\hline
\end{tabular}

Composition of VG formulation: 1:1.

\section{Preparation of VG kwath}

3 gm of VG powder was suspended in $100 \mathrm{ml}$ drinking water, kept overnight, boiled till $50 \%$ water is evaporated, cooled to room temperature and consumed on an empty stomach twice a day for six months under the supervision of an Ayurvedic Physician.

\section{Biochemical parameters}

The fasting and postprandial plasma glucose levels were monitored at monthly intervals, while the glycosylated hemoglobin (HbA1c), biomarkers of oxidative stress viz., Superoxide dismutase (SOD), catalase, reduced glutathione (GSH), Thiobarbituric Acid Reactive Substances (TBARS) and lipid profile, biochemical markers of kidney and liver functions were monitored at baseline, at the middle ( 3 month) and at the end ( 6 month) of the therapy.

Fasting and postprandial plasma glucose was estimated by the Glucose oxidase/Peroxidase method [22]. Glycosylated hemoglobin (HbA1c) was estimated by the ion exchange resin method [23]. Estimation of plasma total cholesterol by the Cholesterol oxidase Phenolaminophenazone CHOD-PAP 


\section{Journal of Complementary Medicine \& Alternative Healthcare}

method [24], triglyceride by GPO-PAP method [25], High density lipoprotein cholesterol (HDL) by Polyethylene glycol/CHOD-PAP method [26], Low-density lipoprotein cholesterol (LDL) and Very-low density lipoprotein cholesterol (VLDL) were calculated by the Friedewald formula, urea by the modified Berthelot method [27], uric acid by uricase/PAP method [28], creatinine by modified Jaffe's kinetic method [29], Alanine transaminase (SGPT or ALT) and serum Aspertate transaminase (SGOT or AST) by the modified International Federation of Clinical Chemistry method [30], and bilirubin by method of L. Jendrassik [31] was assayed using standard kits from Crest Biosystems, Goa (India). Markers of oxidative stress such as super oxide dismutase (SOD) Winterbourn et al. [32], catalase by Sinha, [33], glutathione (GSH) Ellman et al. [34], and Thiobarbituric Acid Reactive Substances (TBARS) Ohkawa et al. [35] were checked.

\section{Ethical clearance}

The study protocol was duly approved by the Institutional Human Ethics Committee (JU/IHEC/2013-A/13).

\section{Statistical analysis}

Statistical analysis was carried out using a paired $t$ test (Sigma stat 3.5 ). A $\mathrm{p}$-value ${ }^{*} \mathrm{p}<0.05,{ }^{* *} \mathrm{p}<0.001$ was considered statistically significant.

\section{Results}

\section{Effect of VG therapy on hyper-glycemia}

Table 3 shows the fasting and postprandial blood glucose levels at monthly intervals in subjects on "VG" therapy. A significant decrease was recorded for fasting $(13.5 \% \mathrm{P}<0.05)$, postprandial $(15.0 \%,<0.001)$ glucose levels and glycosylated hemoglobin $(9.8 \%)$ at the end of six months therapy.

Table 3: Effect of "VG" administration on hyperglycemia in type 2 diabetics.

\begin{tabular}{|c|c|c|c|}
\hline & \multicolumn{2}{|c|}{ Variations in Biochemical Markers of Hyperglycemia During the Course of Therapy } \\
\hline Duration & FPG (mg/dl) & PPBG (mg/dl) \\
\hline Base line values & $168.75 \pm 8.44$ & $256.03 \pm 10.22$ & $245.59 \pm 10.20^{*}$ \\
\hline 1 month & $157.98 \pm 7.63^{*}$ & $237.41 \pm 10.84^{*}$ & $228.97 \pm 10.95^{* *}$ \\
\hline 2 month & $151.45 \pm 7.82^{*}$ & $226.44 \pm 11.52^{* *}$ \\
\hline 3 month & $150.04 \pm 7.78^{*}$ & $219.92 \pm 10.17^{* *}$ \\
\hline 4 month & $148.43 \pm 7.71^{*}$ & $7.25 \pm 0.23^{*}(55.7)$ & $217.47 \pm 10.34^{* *}$ \\
\hline 5 month & $146.58 \pm 5.92^{*}$ & $(60.4)$ & $(\downarrow 15.0 \%)$ \\
\hline 6 month & $145.85 \pm 8.03^{*}$ & $6.93 \pm 0.19^{* *}(52.2)$ & $(\downarrow 9.8 \%)$ \\
\hline
\end{tabular}

Data are expressed as Mean \pm SEM; ${ }^{*} p<0.05 ;{ }^{* *} p<0.001$ compared to Base line values

HDL-High-density lipoprotein cholesterol; LDL-Low-density lipoprotein cholesterol; VLDL- Very- low density lipoprotein cholesterol; TC-Total cholesterol

\section{Effect of VG therapy on lipidemia}

Table 4 shows the results of the lipid profile of patients on "VG" therapy. Total cholesterol, triglycerides, LDL and VLDL were significantly decreased after six months therapy by $9.6 \%, 14.4 \%$, $15.7 \%$, and $14.4 \%$ respectively $(\mathrm{P}<0.05)$. HDL cholesterol was elevated from $32.50 \pm 1.11$ to $35.69 \pm 1.02(\mathrm{P}<0.001)$.

Table 4: Effect of "VG" administration on lipidemia in type 2 diabetics

\begin{tabular}{|c|c|c|c|c|}
\hline Biochemical Parameter & \multicolumn{4}{|c|}{ Variation in Lipid Profile at 3 Month Intervals During the Course of Therapy } \\
\hline & Base line value & 3 Month & 6 Month & Mean (\%) change \\
\hline Total cholesterol (mg/dl) & $143.26 \pm 4.14$ & $134.59 \pm 2.79^{*}$ & $129.42 \pm 3.02^{*}$ & $(\downarrow 9.6 \%)$ \\
\hline Triglyceride (mg/dl) & $147.64 \pm 14.16$ & $128.07 \pm 11.75^{*}$ & $126.33 \pm 7.04^{*}$ & $(\downarrow 14.4 \%)$ \\
\hline HDL- cholesterol (mg/dl) & $32.50 \pm 1.11$ & $34.59 \pm 0.84^{* *}$ & $35.69 \pm 1.02^{* *}$ & $(\uparrow 9.8 \%)$ \\
\hline LDL-cholesterol (mg/dl) & $81.22 \pm 3.30$ & $74.39 \pm 3.04^{*}$ & $68.47 \pm 2.61^{*}$ & $(\downarrow 15.7 \%)$ \\
\hline VLDL (mg/dl) & $29.53 \pm 2.83$ & $25.61 \pm 2.35^{*}$ & $25.27 \pm 1.41^{*}$ & $(\downarrow 14.4 \%)$ \\
\hline TC/HDL Ratio & $4.58 \pm 0.26$ & $3.96 \pm 0.15^{* *}$ & $3.71 \pm 0.15^{* *}$ & $(\downarrow 18.9 \%)$ \\
\hline LDL/HDL Ratio & $2.59 \pm 0.15$ & $2.21 \pm 0.13^{* *}$ & $1.98 \pm 0.11^{* *}$ & $(\downarrow 23.4 \%)$ \\
\hline
\end{tabular}

Data are expressed as Mean $\pm \mathrm{SEM} ;{ }^{*} p<0.05 ;{ }^{* *} p<0.001$ compared to Base line values

HDL-High-density lipoprotein cholesterol; LDL-Low-density lipoprotein cholesterol; VLDL- Very- low density lipoprotein cholesterol; TC-Total cholesterol

\section{Effect of VG therapy on biomarkers of oxidative stress}

Significant $(\mathrm{P}<0.05, \mathrm{P}<0.001)$, improvements in $\mathrm{GSH}$ level (from $1.98 \pm 0.17$ to $2.59 \pm 0.21 \mathrm{mg} / \mathrm{dl}$ ), SOD activity (from
$0.63 \pm 0.05$ to $0.94 \pm 0.08 \mu \mathrm{M} / \mathrm{min} / \mathrm{mg}$ protein), catalase activity (from $7.64 \pm 0.24$ to $9.44 \pm 0.23 \mu \mathrm{M} / \mathrm{min} / \mathrm{mg}$ protein) were recorded. A significant decrease $(\mathrm{P}<0.001)$ in TBARS (from 
$457.19 \pm 8.09$ to $415.15 \pm 7.47$ (moles of Malondialdehyde/ml of blood) were recorded at the end of six months therapy.

\section{Effect of VG therapy on markers of toxicity}

The effect of "VG" therapy on kidney function was monitored by estimating urea, uric acid and creatinine levels in plasma at specified intervals during the course of therapy. The data presented in Table 5 showed significant $(\mathrm{P}<0.05)$, reductions in Urea (from $29.97 \pm 1.20$ to $27.10 \pm 0.88 \mathrm{mg} / \mathrm{dl}$ ) and uric acid (from $5.08 \pm 0.20$ to $4.67 \pm 0.20 \mathrm{mg} / \mathrm{dl}$ ) and notable reduction in creatinine (from $0.78 \pm 0.06$ to $0.73 \pm 0.05$ ) at the end of six months therapy.

Table 5: Effect of "VG" administration on biomarkers of oxidative stress in type 2 diabetics.

\begin{tabular}{|c|c|c|c|c|}
\hline \multirow[t]{2}{*}{ Biochemical Parameter } & \multicolumn{4}{|c|}{ Variation in Biomarkers of Oxidative Stress at 3 Month Intervals During the Course of Therapy } \\
\hline & Baseline values & 3 Months & 6 Months & Mean (\%) change \\
\hline $\mathrm{GSH}:(\mathrm{mg} / \mathrm{ml})$ & $1.98 \pm 0.17$ & $2.40 \pm 0.28$ & $2.59 \pm 0.21^{*}$ & $(\uparrow 30.5 \%)$ \\
\hline SOD:( $\mu \mathrm{M} / \mathrm{min} / \mathrm{mg}$ protein $)$ & $0.63 \pm 0.05$ & $0.80 \pm 0.05$ & $0.94 \pm 0.08^{* *}$ & $(\uparrow 48.4 \%)$ \\
\hline Catalase: $(\mu \mathrm{M} / \mathrm{min} / \mathrm{mg}$ protein $)$ & $7.64 \pm 0.24$ & $8.46 \pm 0.29$ & $9.44 \pm 0.23^{* *}$ & $(\uparrow 23.5 \%)$ \\
\hline $\begin{array}{c}\text { TBARS:(n moles of MDA/ml of } \\
\text { blood) }\end{array}$ & $457.19 \pm 8.09$ & $430.53 \pm 6.52 *$ & $415.15 \pm 7.47^{* *}$ & $(\downarrow 9.1 \%)$ \\
\hline
\end{tabular}

Data are expressed as Mean \pm SEM; ${ }^{*} p<0.05$; ${ }^{* *} p<0.001$ compared to Base line values

GSH: Reduced glutathione; SOD-Superoxide dismutase; TBARS- Thiobarbituric acid reacting substances.

Table 6: Effect of "VG" administration on biochemical markers of toxicity.

\begin{tabular}{|c|c|c|c|c|}
\hline \multirow[t]{2}{*}{ Biochemical Parameter } & \multicolumn{4}{|c|}{ Variation in Biomarker of Toxicity at 3 Month Intervals During the Course of Therapy } \\
\hline & Base line values & 3 Month & 6 Month & Mean (\%) Change \\
\hline Urea (mg/dl) & $29.97 \pm 1.20$ & $28.21 \pm 0.97^{*}$ & $27.10 \pm 0.88^{*}$ & $(\downarrow 9.5 \%)$ \\
\hline Uric acid (mg/dl) & $5.08 \pm 0.20$ & $4.88 \pm 0.22^{*}$ & $4.67 \pm 0.20^{*}$ & $(\downarrow 8.0 \%)$ \\
\hline Creatinine (mg/dl) & $0.78 \pm 0.06$ & $0.73 \pm 0.06$ & $0.73 \pm 0.05$ & $(\downarrow 5.9 \%)$ \\
\hline Total Billurubin (mg/dl) & $0.83 \pm 0.06$ & $0.74 \pm 0.05$ & $0.70 \pm 0.04^{*}$ & $(\downarrow 16.3 \%)$ \\
\hline SGOT (IU/L) & $22.47 \pm 1.61$ & $20.30 \pm 1.47$ & $18.00 \pm 1.04^{*}$ & $(\downarrow 19.9 \%)$ \\
\hline SGPT (IU/L) & $23.60 \pm 2.32$ & $21.55 \pm 2.29$ & $19.26 \pm 1.38$ & $(\downarrow 18.3 \%)$ \\
\hline LDL/HDL Ratio & $2.59 \pm 0.15$ & $2.21 \pm 0.13^{* *}$ & $1.98 \pm 0.11^{* *}$ & $(\downarrow 23.4 \%)$ \\
\hline
\end{tabular}

Data are expressed as Mean \pm SEM; ${ }^{*} p<0.05 ;{ }^{* *} p<0.001$ compared to Base line values.

SGOT- Serum Glutamate Oxaloacetate Transaminase; SGPT- Serum Glutamate Pyruvate Transaminase.

Significant $(\mathrm{P}<0.05)$, variations in biochemical markers of liver functions, namely bilirubin (from $0.83 \pm 0.06$ to $0.70 \pm 0.04$ $\mathrm{mg} / \mathrm{ml}$ ) and SGOT (from $22.47 \pm 1.61$ to $18.00 \pm 1.04 \mathrm{IU} / \mathrm{L}$ ) as well as SGPT (from $23.60 \pm 2.32$ to $19.26 \pm 1.38 \mathrm{IU} / \mathrm{L}$ ), at the end of six months was observed (Table 6).

\section{Effect of VG therapy on hypertension and body mass index}

Table 7: Effect of "VG" therapy on Hypertension \& Body Mass Index.

\begin{tabular}{|c|c|c|c|c|}
\hline & \multicolumn{3}{|c|}{ Variations at 3 Month Intervals During the Course of Therapy } \\
\hline & Base line values & 3 Months & 6 Months & Mean (\%) Change \\
\hline SBP $(\mathrm{mm} \mathrm{Hg})$ & $133.70 \pm 2.59$ & $130.52 \pm 2.45$ & $129.22 \pm 2.39^{*}$ & $(\downarrow 3.3 \%)$ \\
\hline DBP $(\mathrm{mm} \mathrm{Hg})$ & $81.70 \pm 0.97$ & $80.15 \pm 1.02$ & $79.56 \pm 0.93^{*}$ & $(\downarrow 2.6 \%)$ \\
\hline BMI $(\mathrm{kg} / \mathrm{m} 2)$ & $25.21 \pm 0.64$ & $24.56 \pm 0.62^{* *}$ & $24.22 \pm 0.60^{* *}$ & $(\downarrow 3.9 \%)$ \\
\hline
\end{tabular}

Data are expressed as Mean \pm SEM; ${ }^{*} p<0.05 ;{ }^{* *} p<0.001$ compared to Base line values

SBP-Systolic blood pressure; DBP- Diastolic blood pressure; BMI-Body mass index.

Table 7 shows variations in systolic blood pressure (from $133.70 \pm 2.59$ to $129.22 \pm 2.39 \mathrm{mmHg}$ ), diastolic blood pressure (from $81.70 \pm 0.97$ to $79.56 \pm 0.93 \mathrm{mmHg}$ ) and body mass index (from $25.21 \pm 0.64$ to $24.22 \pm 0.60 \mathrm{~kg} / \mathrm{m} 2$ ) at the end of the six months therapy.

\section{Discussion}

Currently, plant based therapies (main or supplementary) are being used globally for the management of type 2 diabetes.
In India, the indigenous systems of medicine viz., Ayurveda, Siddha \& Unani employ plant based extracts for treatment of diabetes (Premeha in Ayurveda). Most of the Ayurveda based formulations depend on plants/herbs based decoctions, and powders. In the present study, administration of the aqueous extract of VG that consisted of equal amounts of the ingredients for over a period of 6 months to type 2 diabetic subjects resulted in significant improvements of altered biochemical markers. 
Significant alleviation in glucose homeostasis, as marked by noticeable changes in glycosylated hemoglobin, blood glucose levels, and lipid profile were observed. The G. sylvestre leaf extracts are reported to reduce hyperglycaemia in experimental animals [16], and human type II diabetics [17]. The G. Sylvestre is reported to promote insulin secretion, probably by regeneration of pancreatic beta cells $[17,18]$. The gymnemagenin and gymnemic acids in $G$. sylvestre, showed to exhibit potent antioxidant, and hepatoprotective activities [36]. Ethanolic extract of $G$. sylvestre was reported to possess anti-apoptotic potential in STZ-induced diabetic cardiomyopathy, and affected the levels of leptin, insulin, dyslipidemia, apolipoproteins, lipids, LDH (serum lactate dehydrogenase) in experimental models [37]. Administration of deacylgymnemic acid DAGA (200mg/kg), a derivative of gymnemic acid reduced Systolic blood pressure and significantly improved the fasting plasma glucose and HOMA-IR (homeostatis model assessment insulin resistance) with marginal improvement in lipid profile [38]. The G. sylvestre is also reported to inhibit absorption of glucose from intestine. The atomic arrangement of gymnemic acid molecules is similar to that of glucose molecules and they reduce the blood glucose level by preventing the absorption of sugar molecule in the intestine. It is attributed by filling the receptor location in the absorptive external layer of the intestine by gymnemic acid molecules [39].

In a controlled study, an aqueous extract of the leaves of G. sylvestre, (GS4) when administered at the dose of $400 \mathrm{mg} /$ day, to subjects with insulin-dependent diabetes mellitus (IDDM), the insulin requirement came down together with fasting blood glucose, HbA1c and serum lipid levels soon after therapy. However, the GS4 administration failed to check glycosylated haemoglobin and glycosylated plasma protein levels on long term follow up. The GS4 therapy is reported to enhance insulin secretion rate, either by regeneration or revitalisation of the beta cells [40].

The effectiveness of GS4, further investigated as a supplementary drug to conventional oral anti-hyperglycemic drugs. Administration of GS4 (400mg/day) to 22 Type 2 diabetic patients receiving conventional therapy resulted in significant reductions in blood glucose and, glycosylated hemoglobin level. In addition, five of the 22 diabetic patients showed improved glycemic control with GS4 alone and were discontinue their conventional drug [17].

In another study, supplementation of the diet with $G$. sylvestre at the dose of $500 \mathrm{mg}$ per day for a period of 3 months reduced polyphagia, fatigue, blood glucose levels with concurrent reductions in $\mathrm{HbA1c}$, lipid profile suggesting beneficial effect of $G$. sylvestre supplementation in the management of diabetes mellitus [41].

Pterocarpus marsupium is traditionally used in Indian ayurvedic medicine for the treatment of diabetes and has been shown to control diabetes in experimental animals [42]. The phenolic C-glycosides present in P. marsupium regulated glucose homeostasis and significantly decreased the TNF- $\alpha$ level in experimental diabetes [43]. The phenolics, marsupsin, pterosupin, pterostilbene and (-)-epicatechin present in $P$. marsupium have been identified as the blood sugar lowering components $[20,44]$.

The alcohol extract of the bark of P. marsupium Roxb shown to exhibit potent antidiabetic activity and corrected the metabolic alterations in diabetic rats [42]. Aqueous extracts of $P$. marsupium Linn significantly attenuated hyper insulinaemia as well as hypertriglyceridaemia and also prevented the alteration in metabolic patterns [45]. The Indian Council of Medical Research undertook an anti-diabetic phase II open trial at four centers across Indian using Vijaysar (Pterocarpus marsupium). Vijaysar was tested in newly-diagnosed or untreated non-insulin dependent diabetes mellitus (NIDDM) patients between 35 and 60 age for 12 weeks. Among the 93 patients who completed 12 wk of treatment, both the fasting and postprandial blood glucose levels fell significantly ( $\mathrm{P}<0.001)$, by 32 and $45 \mathrm{mg} / \mathrm{dl}$ at $12 \mathrm{wk}$ from the initial means of 151 and $216 \mathrm{mg} / \mathrm{dl}$ respectively. Mean HbA1c Other laboratory parameters remained stable during the designated treatment period of $12 \mathrm{wk}$. Also, no side-effects were reported [46].

Our previous study done with the polyherbal formulation, "GSPF kwath" which contains Vijaysar and Gurmar as two of the ingredients has shown antidiabetic and antioxidative effects [13]. "GSPF kwath", showed $23.5 \%, 26.7 \%$ and $11.7 \%$ reductions in fasting, postprandial blood glucose and $\mathrm{HbA} 1 \mathrm{c}$ respectively. In the present study "VG" containing only two of the components of GSPF proved highly beneficial in restoring not only hyperglycemia but also lipidemia and antioxidative potential. The changes observed on glycemic, lipidemic and oxidative stress. Oral administration of "VG" therapy for 6 months had no adverse effects, either on kidney or liver functions and in fact showed a significant improvement in the functioning of these vital organs.

\section{Conclusion}

In conclusion, the "VG" administration to type 2 diabetic patients with varying degrees of glycemia, lipidemia and oxidative stress provide an efficient alternative to conventional antidiabetic drugs when coupled with active lifestyle and dietary changes. Significant decrease in biochemical markers viz., blood glucose, HbA1c, total cholesterol, triglycerides, LDL-cholesterol, and VLDL-cholesterol and higher values of HDL, following VG therapy are testimony to the anti-diabetic efficacy of VG. Further, the formulation did not show any adverse effects on liver and kidney functions and may be a potential natural and safe therapy for treatment and prevention of diabetic complications but randomized controlled trials are required to confirm these findings.

\section{Acknowledgment}

We thank M/S Dindayal Industries Ltd., Gwalior (M.P.) for the supply of the Vijaysaar and Gurmar powder and the financial support from AYUSH, New Delhi, (F.NO. Z.31014/02/2009/ EMR-CCARS) is duly acknowledged. We are grateful to all the 
human subjects who volunteered to participate in the study. Our profound thanks extend to colleagues of the laboratory and students for their unreserved support in conducting this study.

\section{Referencers}

1. American Diabetes Association (2011) Diagnosis and classification of diabetes mellitus. Diabetes Care 33 (Suppl 1): S62-69.

2. Del Prato S (2009) Role of glucotoxicity and lipotoxicity in the pathophysiology of Type 2 diabetes mellitus and emerging treatment strategies. Diabet Med 26(12): 1185-1192.

3. Hamamdzic D, Wilensky RL (2013) Porcine models of accelerated coronary atherosclerosis: role of diabetes mellitus and hypercholesterolemia. Journal of diabetes research 2013:1-7.

4. Torimoto K, Okada Y, Mori H, Otsuka T, Kawaguchi M, et al. (2015) Effects of exenatide on postprandial vascular endothelial dysfunction in type 2 diabetes mellitus. Cardiovasc Diabetol 14(25): 1-8.

5. Kaatabi H, Bamosa AO, Badar A, Al-Elq A, Abou-Hozaifa B, et al. (2015) Nigella sativa improves glycemic control and ameliorates oxidative stress in patients with type 2 diabetes mellitus: placebo controlled participant blinded clinical trial. PLoS One 10(2):1-15.

6. Xu F, Zhao LH, Su JB, Chen T, Wang XQ, et al. (2014) The relationship between glycemic variability and diabetic peripheral neuropathy in type 2 diabetes with well-controlled HbA1c. Diabetol Metab Syndr 6 (1): 139.

7. Tsang MW (2012) The management of type 2 diabetic patients with hypoglycaemic agents. ISRN Endocrinol 2012: 1-9.

8. Krentz AJ, Bailey CJ (2005) Oral antidiabetic agents: current role in type 2 diabetes mellitus. Drugs 65(3): 385-411.

9. Daido H, Horikawa Y, Takeda J (2014) The effects of pitavastatin on glucose metabolism in patients with type 2 diabetes with hypercholesterolemia. Diabetes Res Clin Pract 106(3): 531-537.

10. Sudha P, Zinjarde SS, Bhargava SY, Kumar AR. (2011) Potent $\alpha$-amylase inhibitory activity of Indian Ayurvedic medicinal plants. BMC Complement Altern Med 11(5): 1-10.

11. Nain P, Saini V, Sharma S, Nain J (2012) Antidiabetic and antioxidant potential of Emblica officinalis Gaertn. Leaves extract in streptozotocininduced type-2 diabetes mellitus (T2DM) rats. J Ethnopharmacol 142 (1): 65-71.

12. Rai PK, Gupta SK, Srivastava AK, Gupta RK, Watal G (2013) A Scientific Validation of Antihyperglycemic and Antihyperlipidemic Attributes of Trichosanthes dioica. ISRN Pharmacol 2013: 1-7.

13. Mahajan S, Chauhan P, Subramani SK, Anand A, Borole D, et al. (2015) Evaluation of "GSPF kwath": A Gymnema sylvestre-containing polyherbal formulation for the treatment of human type 2 diabetes mellitus. European Journal of Integrative Medicine 7(3): 303-311.

14. Mahajan S, Singh N, Subramanian SK, Chauhan P, Saxena S, et al. (2013) "Diabegon", a safe and effective polyherbal therapy for type 2 diabetes mellitus. World J Transl Med 2(3): 75-82.

15. Ramkumar KM, Vanitha P, Uma C, Suganya N, Bhakkiyalakshmi E, et al. (2011) Antidiabetic activity of alcoholic stem extract of Gymnema montanum in streptozotocin-induced diabetic rats. Food Chem Toxicol 49(12): 3390-3394.

16. Shanmugasundaram KR, Panneerselvam C, Samudram P, Shanmugasundaram ER. (1983) Enzyme changes and glucose utilisation in diabetic rabbits: the effect of Gymnema sylvestre, R.Br. J Ethnopharmacol 7 (2): 205-234.

17. Baskaran K, Kizar Ahamath B, Radha Shanmugasundaram K, Shanmugasundaram ER (1990) Antidiabetic effect of a leaf extract from Gymnema sylvestre in non-insulin-dependent diabetes mellitus patients. J Ethnopharmacol 30(3): 295-300.
18. Persaud SJ, Al-Majed H, Raman A, Jones PM (1999) Gymnema sylvestre stimulates insulin release in vitro by increased membrane permeability. J Endocrinol 163(2): 207-212.

19. Kameswara Rao B, Giri R, Kesavulu MM, Apparao C (2001) Effect of oral administration of bark extracts of Pterocarpus santalinus L. on blood glucose level in experimental animals. J Ethnopharmacol 74(1): 69-74.

20. Mishra A, Srivastava R, Srivastava SP, Gautam S, Tamrakar AK, et al. (2013) Antidiabetic activity of heart wood of Pterocarpus marsupium Roxb. and analysis of phytoconstituents. Indian J Exp Biol 51(5): 363374.

21. Rizvi SI, Mishra N (2013) Traditional Indian medicines used for the management of diabetes mellitus. J Diabetes Res 2013: 1-11.

22. Raabo E, Terkildsen TC (1960) On the enzymatic determination of blood glucose. Scand J Clin Lab Invest 1960; 12(4): 402-407.

23. Trivelli LA, Ranney HM, Lai HT (1971) Hemoglobin components in patients with diabetes mellitus. N Engl J Med 284(7): 353-357.

24. Stockbridge H, Hardy RI, Glueck CJ (1989) Public cholesterol screening: motivation for participation, follow-up outcome, self-knowledge, and coronary heart disease risk factor intervention. J Lab Clin Med 114(2): 142-151.

25. Fossati P, Prencipe L (1982) Serum triglycerides determined colorimetrically with an enzyme that produces hydrogen peroxide. Clin Chem 28(10): 2077-2080.

26. Lopes-Virella MF, Stone P, Ellis S, Colwell JA (1977) Cholesterol determination in high-density lipoproteins separated by three different methods. Clin Chem 23(5): 882-884.

27. Fawcett JK, Scott JE (1960) A rapid and precise method for the determination of urea. J Clin Pathol 13(2): 156-159.

28. Fossati P, Prencipe L, Berti G (1980) Use of 3,5-dichloro-2hydroxybenzenesulfonic acid/4- aminophenazone chromogenic system in direct enzymic assay of uric acid in serum and urine. Clin Chem 26(2): 227-231.

29. Bowers LD, Wong ET (1980) Kinetic serum creatinine assays. II. A critical evaluation and review. Clin Chem 26(5): 555-561.

30. Reitman S, Frankel S (1957) A colorimetric method for the determination of serum glutamic oxalacetic and glutamic pyruvic transaminases. Am J Clin Pathol 28(1):56-63.

31. Fuehr J (1964) Bilirubin determination in the serum according to the method of L. Jendrassik, R.A. Cleghorn and P. Grof. Med Monatsschr 18: 183-184.

32. Winterbourn CC, Hawkins RE, Brian M, Carrell RW (1975) The estimation of red cell superoxide dismutase activity. J Lab Clin Med 85(2): 337-341.

33. Sinha AK (1972) Colorimetric assay of catalase. Anal Biochem 47(2): 389-394.

34. Ellman GL (1959) Tissue sulfhydryl groups. Arch Biochem Biophys 82(1): 70-77.

35. Ohkawa H, Ohishi N, Yagi K (1979) Assay for lipid peroxides in animal tissues by thiobarbituric acid reaction. Anal Biochem 95(2): 351-358.

36. Kang MH, Lee MS, Choi MK, Min KS, Shibamoto T (2012) Hypoglycemic activity of Gymnema sylvestre extracts on oxidative stress and antioxidant status in diabetic rats. J Agric Food Chem 60(10): 25172524.

37. Kumar V, Bhandari U, Tripathi CD, Khanna G (2012) Evaluation of antiobesity and cardioprotective effect of Gymnema sylvestre extract in murine model. Indian J Pharmacol 44(5): 607-613.

38. Bhansali S, Shafiq N, Pandhi P, Singh AP, Singh I, et al. (2013) Effect of a deacyl gymnemic acid on glucose homeostasis \& metabolic parameters 
in a rat model of metabolic syndrome. Indian J Med Res 137(6):11741179 .

39. Sahu NP, Mahato SB, Sarkar SK, Poddar G (1996) Triterpenoid saponins from Gymnema sylvestre. Phytochemistry 41(4): 1181-1195.

40. Shanmugasundaram ER, Gopinath KL, Radha Shanmugasundaram K, Rajendran VM (1990) Possible regeneration of the islets of Langerhans in streptozotocin-diabetic rats given Gymnema sylvestre leaf extracts. J Ethnopharmacol 30 (3): 265-279.

41. Kumar SN, Mani UV, Mani I (2010) An open label study on the supplementation of Gymnema sylvestre in type 2 diabetics. J Diet Suppl $7(3): 273-282$.

42. Dhanabal SP, Kokate CK, Ramanathan M, Kumar EP, Suresh B (2006) Hypoglycaemic activity of Pterocarpus marsupium Roxb. Phytother Res 20(1): 4-8.

This work is licensed under Creative

Commons Attribution 4.0 License

DOI: 10.19080/JCMAH.2018.07.555718
43. Halagappa K, Girish HN, Srinivasan BP (2010) The study of aqueous extract of Pterocarpus marsupium Roxb. on cytokine TNF- $\alpha$ in type 2 diabetic rats. Indian J Pharmacol 42(6): 392-396.

44. Maurya R, Singh R, Deepak M, Handa SS, Yadav PP, et al. (2004) Constituents of Pterocarpus marsupium: an ayurvedic crude drug. Phytochemistry 65(7): 915-920.

45. Grover JK, Vats V, Yadav SS (2005) Pterocarpus marsupium extract (Vijayasar) prevented the alteration in metabolic patterns induced in the normal rat by feeding an adequate diet containing fructose as sole carbohydrate. Diabetes Obes Metab 7(4): 414-420.

46. ICMR (1998) Flexible dose open trial of vijayasar in cases of newlydiagnosed non-insulin dependent diabetes mellitus. Indian Council of Medical Research (ICMR) collaborating centers, Central biostatistical monitoring unit, Chennai and central technical co-ordinating unit, ICMR, New Delhi. Indian J Med Res 108: 24-29.

\section{Your next submission with Juniper Publishers will reach you the below assets}

- Quality Editorial service

- Swift Peer Review

- Reprints availability

- E-prints Service

- Manuscript Podcast for convenient understanding

- Global attainment for your research

- Manuscript accessibility in different formats

( Pdf, E-pub, Full Text, Audio)

- Unceasing customer service

Track the below URL for one-step submission https://juniperpublishers.com/online-submission.php 